\title{
Experimental Study on Flame Merging Behavior from 2 by 3 Configuration Model Fire Sources
}

\section{Osami SUGAWA ${ }^{1 *}$ and Yasushi OKA ${ }^{2}$}

\author{
1) Center for Fire Science and Technology, Tokyo University of Science, Noda \\ 2641 Yamasaki, Noda-shi, Chiba, 278-8510, Japan \\ 2) Department of Safety Engineering, Yokohama National University \\ 79-5 Tokiwadai, Hodogaya-ku, Yokohama, 240-8501, Kanagawa, Japan
}

\begin{abstract}
Experimental study was carried out to understand the flame merging behavior from multiple fire sources placed in 2 arrays consisted of three separate fire sources within each array (2 by 3 configuration) without external winds. The sand burner with a diameter of $0.2 \mathrm{~m}$ was used as an unit burner and LPG was employed as a fuel. The distances between two arrays, Sy, and between fire sources separated, Sx, in each array were changed systematically to characterize the flame height and merging behavior due to space effect of multiple fire sources. The height from the edge of the burner to artificial floor level was also changed to estimate the floor effect on flame merging behavior. Visual observation of merged flame height was performed aided by video images to estimate the averaged flame height. Temperatures and upward velocities in the regions of flame(s) and lower part of the plume(s) were measured using a rake of thermocouples and bi-directional probes. Empirical formulae to estimate the merged flame height were developed considering spacing effect between the fire sources separated. The validity of these models was confirmed from the comparison with the experimental data.
\end{abstract}

Key Words: Multi Fire Sources, Merging, Flame, Space, 2 by 3 Configuration, Floor effect

\section{INTRODUCTION}

In the city fires emerged after the Great Hanshin Earthquake (1995 in Japan), the developments of merged flames or flames affected by nearby flames in the firing zone were observed during the propagation of the city fire, and these flames propagated outward from some fire origins. These flames in firing zone were also affected by the large scale convective flow, which was induced by large thermal from many houses burnt in the central area of the fired zone, from unburned area toward burnt area through the paths and alleys between many houses. Spaces around the house, as well as width and configuration of alleys and narrow paths between houses, affected the merging behavior of flames and their height. Flame height becomes one of the clear indexes to assess the fire hazard in the fire fighting being carried out in city fire site. Flame behavior, height and merging behavior in firing zone depend on the spacing distance around the burning buildings and/or wooden houses and cross-wind (or convective flow induced by large thermal).

Deterministic and/or empirical formulae on a diffusion plume and flame behavior, including flame height from a line fire source and a square (or circular) fire source, have been well established [1-8]. However, flame height due to multi-fire sources were concerned by a few

* O.S.has moved to Tokyo University of Science, Suwa, 5000-1 Toyohira, Chino 391-0292, Japan

FIRE SAFETY SCIENCE--PROCEEDINGS OF THE SEVENTH INTERNATIONAL SYMPOSIUM, pp. 891-903 
papers [9-11]. Sugawa and Takahashi [12] have reported the simple model to estimate the merged flame height for two line fires in parallel configuration and for 3 and 4-pools fire in symmetric configuration without wind. Their model is also applicable to estimate the flame height when the burner was placed in and near a corner and in the situation of a burner approaches to a wall.

The purpose of the current work is to develope the previous simple model applicable for the estimation on the merged flame height from six separate fire sources which are placed in 2 arrays of 3 rows (imaging the smallest plane unit of the neighbor houses in the form of 2 by 3 configuration with a path and alleys) without wind effect. Attempts have also been done to understand experimentally on the flow structure on the standing points of temperature and upward velocity which were induced by the merged flame(s).

\section{MODELING on MERGED FLAME HEIGHT}

The starting idea to develop the simple model for estimating the merged flame(s) height from multiple fire sources is that the idea employed on the merged flame from two line fire sources in parallel configuration and from three or four circular fire sources [12]. The correction factor, Fs, on the merged flame height from two paralleled rectangular fire sources is given in equation (1) considering spacing distance between line fire sources, S, width D (shorter length of the line fire source), length W (longer length of the line fire source) and the merged flame height, $L m$, without any separation :

$$
\frac{L}{L_{m}}=F_{s}^{2 / 3}=\left\{\frac{2 D W+S^{2}}{2\left(D W+S^{2}\right)}\right\}^{2 / 3}
$$

As shown in Figure 1, the basic distribution for this experimental study consists of two arrays including three separated fire sources with the same separation distance of $\mathrm{S}_{\mathrm{x}}$ and these apparent array were placed in parallel configuration with the separation of $\mathrm{S}_{\mathrm{y}}$ between them. The array length, $3 \mathrm{D}+2 \mathrm{~S}_{\mathrm{x}}$, corresponds to the length of $\mathrm{W}$ in equation (1) and $\mathrm{S}_{\mathrm{y}}$ corresponds to $\mathrm{S}$, respectively. Then the new correction factor on flame merged can be represented in general form as equation (2):

$$
F s=\frac{2 D\left(3 D+2 S_{x}\right)+S_{y}{ }^{2}}{2\left\{D\left(3 D+2 S_{x}\right)+S_{y}{ }^{2}\right\}}
$$

The dimensionless merged flame height at arbitrary situation, $L / L_{m}$, is adopted taking the $\mathrm{Lm}$ as the reference that of the maximum flame height without any separations. However, 
discrete fire sources make different spacing behavior for $\mathrm{x}$-and $\mathrm{y}$-directions respectively so that it is necessary to treat and present the distribution in dimensionless form. We adopted the unit length of $D o$ for the x-direction because they have two characteristic lengths of D and $\mathrm{S}_{\mathrm{x}}$. Considering the interaction between flames from two apparent arrays of fire sources, we adopted the dimensionless separation as $S_{y} / D$. Enlargement of the inner distance, $S_{x}$, brings about the increase of air entrainment into the flame region merged and which results in shortening the merged flame(s) height. Let us assume the power in equation (3) contains the space factor, $\mathrm{S}_{\mathrm{x}} / \mathrm{D}$, which control the merged flame height depending on the inner separation and also which must fall in the value of $n=2 / 3$ [12] when the no $S_{x}$ is set to the system. Considering the number of separations within the array, $2 S_{x}$, in this case, we employed the term of $2 /\left[3 \cdot\left(1+2 \cdot S_{x} / D\right)\right]$ as the power to the correction factor. Then the equation (3) presents the case that the same heat release rate (HRR) are given for both apparent arrays of the fire sources, $\mathrm{Q}_{1}=\mathrm{Q}_{2}$ with floor effect;

$$
\frac{L}{L_{m}}=\left[\frac{\frac{2 D\left(3 D+2 S_{x}\right)}{D o^{2}}+{\frac{S_{y}}{D^{2}}}^{2}}{2\left\{\frac{D\left(3 D+2 S_{x}\right)}{D o^{2}}+{\frac{S_{y}}{D^{2}}}^{2}\right\}}\right]^{\frac{2}{3\left(1+2 \frac{S_{x}}{D}\right)}}
$$

In the case that HRR from one apparent array of fire source is different from the other, the flame(s) from the array of smaller HRR should tilt toward the flame(s) from the greater HRR, and the merged flame height will be governed by flame(s) from the greater HRR. Therefore, the value of power to the correction factor becomes the similar term of $2 / 5$ for square burner with modification of inner spacing effect as well as the previous equation, thus we obtain the term as $2 /\left[5 \cdot\left(1+2 S_{x} / D\right)\right]$. The merged flame height as an arbitrary separation with different HRR system, $Q_{1}>Q_{2}$, can be presented by the equation (4) with floor effect;

$$
\frac{L}{L_{m}}=\left[\frac{\frac{2 D\left(3 D+2 S_{x}\right)}{D o^{2}}+{\frac{S_{y}}{D^{2}}}^{2}}{2\left\{\frac{D\left(3 D+2 S_{x}\right)}{D o^{2}}+{\frac{S_{y}}{D^{2}}}^{2}\right\}}\right]^{\frac{2}{5\left(1+2 \frac{S_{x}}{D}\right)}}
$$

Let us consider the case that the flame(s) emerge from an opened roof or from the opened windows of the upper part of a residential house, it could be expected that the less interaction between nearby flame(s) and which bring about the shortening of the merged flame height. Because ambient air can entrain not only into the flame directory but also through the base part and/or lower part of the flame(s) and flow by these convection gives the sufficient air for combustion reaction and it results in the less interaction between nearby flames. We also assumed that the ambient air can entrain from both sides of the apparent array of fire sources so that twice of the space effect is expected as $2 S_{y}$, with reducing the exponent to half on the flame merging. Then, for the case of equal HRRs from both apparent arrays of the fire sources, $Q_{1}=Q_{2}$ without floor effect, we present the merged flame height is modeled by equation (5); 


$$
\left.\frac{L}{L_{m}}=\left[\frac{\frac{2 D\left(3 D+2 S_{x}\right)}{D o^{2}}+\left(\frac{2 S_{y}}{D}\right)^{2}}{2\left\{\frac{D\left(3 D+2 S_{x}\right)}{D o^{2}}+\left(\frac{2 S_{y}}{D}\right)^{2}\right\}}\right]\right]^{\frac{1}{3\left(1+2 \frac{S_{x}}{D}\right)}}
$$

The same idea is applied to the case which have different HRR from respective two apparent arrays of fire sources without floor effect. The similar model based on equation (5) is developed for the case of $\mathrm{Q}_{1}>\mathrm{Q}_{2}$ considering the condition of without floor effect;

$$
\frac{L}{L_{m}}=\left[\frac{\frac{2 D\left(3 D+2 S_{x}\right)}{D o^{2}}+\left(\frac{2 S_{y}}{D}\right)^{2}}{2\left\{\frac{D\left(3 D+2 S_{x}\right)}{D o^{2}}+\left(\frac{2 S_{y}}{D}\right)^{2}\right\}}\right] \overline{5\left(1+2 \frac{S_{x}}{D}\right)}
$$

\section{EXPERIMENTS}

2 by 3 configuration

As shown in Figures 1, cylinder shaped six gas diffusion burners of $0.2 \mathrm{~m}$ diameter with $0.3 \mathrm{~m}$ high were set in 2 by 3 configuration in the still atmosphere. Liquefied petroleum gas, LPG, was employed as a fuel and which was supplied to each burner through each gas flow meter. The HRR of the first array of fire sources were set at $22.5 \mathrm{~kW}$ in total $\left(7.5 \mathrm{~kW} \times 3\right.$ burners, $\left.\mathrm{Q}_{1}\right)$ and that for the second array was varied in the range of $22.5 \mathrm{~kW}$ to $67.5 \mathrm{~kW}$ in total (changing from 7.5 to $22.5 \mathrm{~kW}$ for each burner, $\mathrm{Q}_{2}$ ).

A movable floor, made of ceramic board with $25 \mathrm{~mm}$ thick, was also set around the burners to generate the floor effect on flame merging behavior. The distance from the burner edge to its surface, $h$ in Figure 2, was changed within the range of $0 \mathrm{~m}$ (the same level to burner surface), $-0.1 \mathrm{~m},-0.2 \mathrm{~m}$, and $-0.3 \mathrm{~m}$.

Temperatures and upward velocities were measured using K-type thermocouples of a diameter of $0.32 \mathrm{~mm}$ and bidirectional probes connected to the precious pressure transducers, respectively. These were installed on a movable rake and that was moved systematically to cover the half region of $0.5 \mathrm{~m}(\mathrm{~L}) \times 0.6 \mathrm{~m}(\mathrm{~W}) \times 1.25 \mathrm{~m}(\mathrm{H})$ by every $0.05 \mathrm{~m}$ separation. Figure 2 shows the measuring positions and which were covered by the rake system. The neighbor images of the flames were recorded by an usual VTR system. Flame(s) heights in each image were processed to evaluate the mean flame height and its deviations.

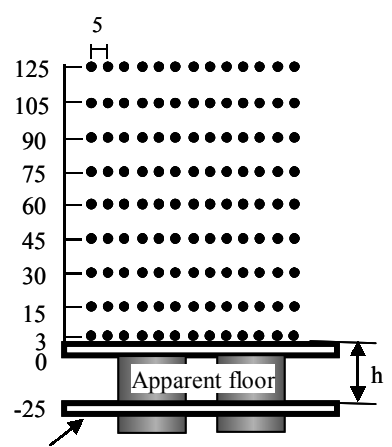
without floor condition

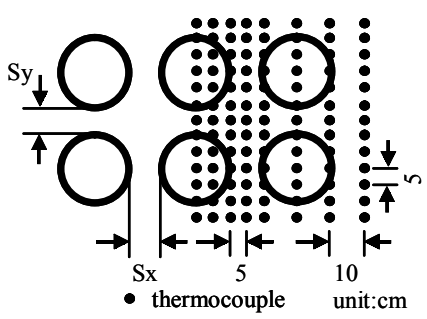

Figure 2 Elevation and plan views of measuring positions of temperature and upward velocity. Dots are the measuring positions. Thick circles are fire sources of $0.2 \mathrm{m \phi}$. 


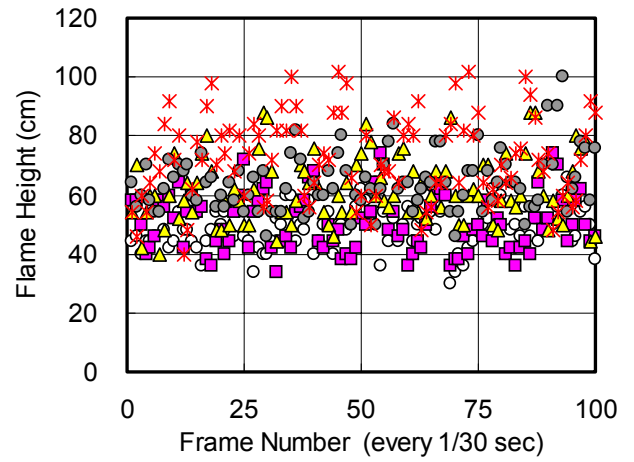

\begin{tabular}{|ccc|}
\hline$\circ \mathrm{Q} 1: \mathrm{Q} 2=1: 1$ & $\square \mathrm{Q} 1: \mathrm{Q} 2=1: 1.5$ & $\Delta \mathrm{Q} 1: \mathrm{Q} 2=1: 2$ \\
$\mathrm{Sx}=0 \mathrm{~cm}, \mathrm{Sy}=0 \mathrm{~cm}$ & $\mathrm{Sx}=0 \mathrm{~cm}, \mathrm{Sy}=0 \mathrm{~cm}$ & $\mathrm{Sx}=0 \mathrm{~cm}, \mathrm{Sy}=1 \mathrm{~cm}$ \\
$\circ \mathrm{Q} 1: \mathrm{Q} 2=1: 2.5$ & $* \mathrm{Q} 1: \mathrm{Q} 2=1: 3$ & \\
$\mathrm{Sx}=0 \mathrm{~cm}, \mathrm{Sy}=2 \mathrm{~cm}$ & $\mathrm{Sx}=0 \mathrm{~cm}, \mathrm{Sy}=3 \mathrm{~cm}$ & \\
\hline
\end{tabular}

Figure 3 Time sequence of flame heights in various HRR and spacing conditions.

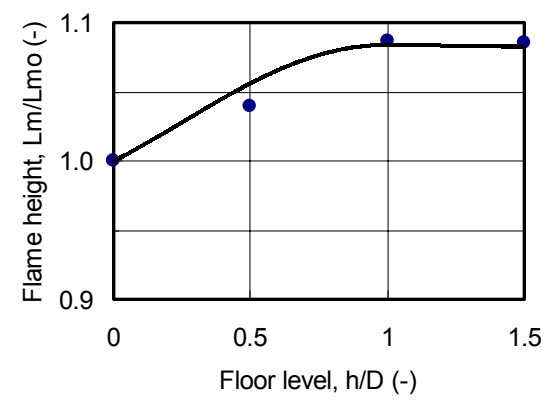

Figure 4 Dimensionless flame heights vs dimensionless elevation.

\section{RESULTS AND DISCUSSIONS}

(a) Flame height merged

Figure 3 shows the typical sequence of the flame heights (continuous flame height) of
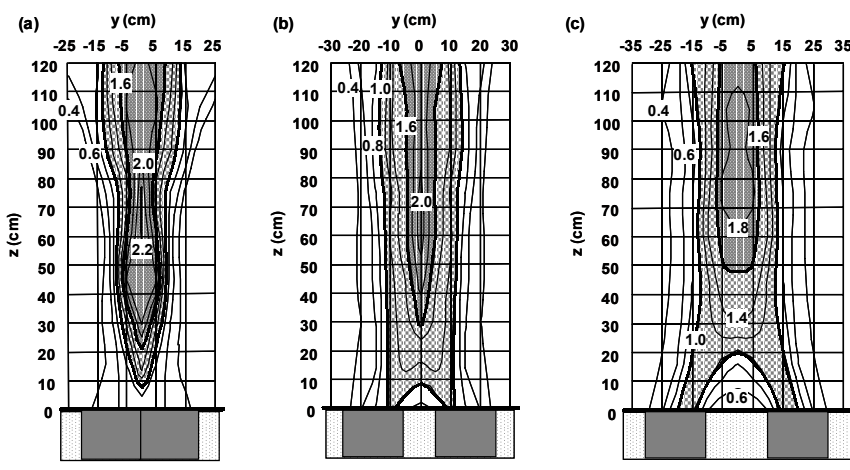
100 successive images (ca. $3 \mathrm{sec}, 1 / 30 \mathrm{sec}$ interval) with the space setting of $\mathrm{Sx}=0.3 \mathrm{~m}$ and $\mathrm{Sy}=0.0 \mathrm{~m}$ changing the $\mathrm{HRR}$ ratio of $\mathrm{Q}_{1} / \mathrm{Q}_{2}=1$ to $\mathrm{Q}_{1} / \mathrm{Q}_{2}=3$ with floor $(\mathrm{h}=0 \mathrm{~m})$ condition. Flame heights, observed at the delineation of continuous flame, irrespective of merged or not, were estimated as the timeaveraged flame height based

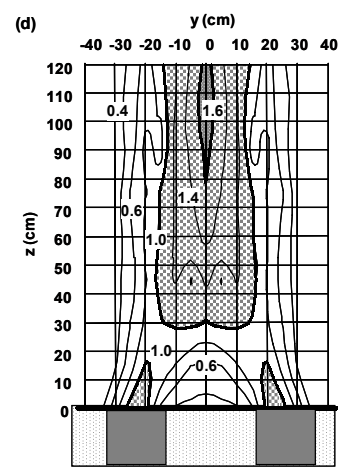

The contour diagram of upward velocity under the various experimental condition.

(a) $Q_{1}=Q_{2}=7.5 \mathrm{~kW}, \quad \mathrm{Sx} / \mathrm{D}=0.0, \quad \mathrm{Sy} / \mathrm{D}=\mathbf{0 . 0}$, with fl oor

(b) $\mathrm{Q}_{1}=\mathrm{Q}_{2}=7.5 \mathrm{~kW}, \mathrm{Sx} / \mathrm{D}=0.0, \mathrm{Sy} / \mathrm{D}=0.5$, with floor

(c) $\mathrm{Q}_{1}=\mathrm{Q}_{2}=7.5 \mathrm{~kW}, \mathrm{Sx} / \mathrm{D}=0.0, \quad \mathrm{Sy} / \mathrm{D}=1.0$, with floor

(d) $\mathrm{Q}_{1}=\mathrm{Q}_{2}=7.5 \mathrm{~kW}, \mathrm{Sx} / \mathrm{D}=0.0, \quad \mathrm{Sy} / \mathrm{D}=1.5$, with floor

(e) $Q_{1}=Q_{2}=7.5 \mathrm{~kW}, \quad \mathrm{Sx} / \mathrm{D}=0.0, \quad \mathrm{Sy} / \mathrm{D}=0.5$, without floor

Figure 5-1 Contour maps of the equi-upward velocity, with and without floor.

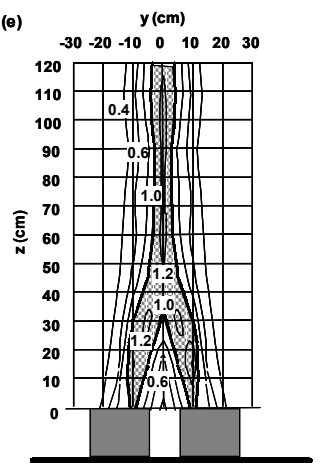

on these sequence of image data. The maximum, minimum, mean continuous flame height and its standard deviation were then e v a l u a t e d. Th e representative mean flame heights and its standard deviation are tabulated in Table 1-1 to 1-8.

We investigated firstly the floor effect on the merged flame height by changing the elevation, $\mathrm{h}$, between floor to the burner surface without the separations between the fire sources $(\mathrm{Sx}=\mathrm{Sy}=0 \mathrm{~cm})$. Figure 4 shows the flame 
Table 1-1 Mean and Std. of flame height $(\mathrm{cm})$ with floor, $\mathrm{Sx} / \mathrm{D}=0.0$ mean

standard deviation

\begin{tabular}{|c|c|c|c|c|c|}
\hline \multirow{2}{*}{$\begin{array}{c}\text { Sy/D } \\
(-)\end{array}$} & \multicolumn{5}{|c|}{ Q1/Q2 (Ratio of HRRs) } \\
\cline { 2 - 6 } & 1.0 & 1.5 & 2.0 & 2.5 & 3.0 \\
\hline 0.0 & 48.6 & 50.3 & 61.7 & 64.2 & 72.5 \\
\hline 0.5 & 38.0 & 45.4 & 50.9 & 58.7 & 71.1 \\
\hline 1.0 & 33.0 & 38.5 & 47.2 & 55.4 & 60.0 \\
\hline 1.5 & 32.7 & 39.0 & 46.8 & 54.2 & 57.1 \\
\hline 2.0 & 32.0 & 39.0 & 45.0 & 51.2 & 56.1 \\
\hline 3.0 & 31.8 & 38.7 & 43.5 & 51.6 & 56.5 \\
\hline 5.0 & 31.8 & 39.8 & 45.3 & 52.4 & 56.2 \\
\hline
\end{tabular}

\begin{tabular}{|c|c|c|c|c|c|}
\hline \multirow{2}{*}{$\begin{array}{c}\text { Sy/D } \\
(-)\end{array}$} & \multicolumn{5}{|c|}{ Q1/Q2 (Ratio of HRRs) } \\
\cline { 2 - 6 } & 1.0 & 1.5 & 2.0 & 2.5 & 3.0 \\
\hline 0.0 & 7.1 & 9.6 & 11.3 & 9.7 & 14.4 \\
\hline 0.5 & 5.7 & 7.5 & 7.9 & 10.5 & 12.1 \\
\hline 1.0 & 5.3 & 6.2 & 6.7 & 7.9 & 10.3 \\
\hline 1.5 & 5.9 & 5.6 & 7.5 & 8.8 & 9.2 \\
\hline 2.0 & 5.4 & 5.9 & 5.9 & 8.1 & 8.5 \\
\hline 3.0 & 4.9 & 5.9 & 6.5 & 7.3 & 8.1 \\
\hline 5.0 & 4.9 & 5.5 & 6.8 & 7.1 & 8.0 \\
\hline
\end{tabular}

Table 1-2 Mean and Std. of flame height $(\mathrm{cm})$ with floor, $\mathrm{Sx} / \mathrm{D}=0.5$ mean

\begin{tabular}{|c|c|c|c|c|c|}
\hline \multirow{2}{*}{$\begin{array}{c}\text { Sy/D } \\
(-)\end{array}$} & \multicolumn{5}{|c|}{ Q1/Q2 (Ratio of HRRs) } \\
\cline { 2 - 6 } & 1.0 & 1.5 & 2.0 & 2.5 & 3.0 \\
\hline 0.0 & 40.0 & 45.5 & 52.3 & 55.3 & 60.6 \\
\hline 0.5 & 34.6 & 41.2 & 47.3 & 52.5 & 57.9 \\
\hline 1.0 & 32.1 & 39.4 & 46.3 & 51.8 & 56.5 \\
\hline 1.5 & 32.2 & 39.4 & 44.1 & 51.6 & 57.0 \\
\hline 2.0 & 32.0 & 39.0 & 43.9 & 51.4 & 57.0 \\
\hline 3.0 & & & & & \\
\hline 5.0 & 32.0 & 39.0 & 43.8 & 51.9 & 56.5 \\
\hline
\end{tabular}
standard deviation

Table 1-3 Mean and Std. of flame height $(\mathrm{cm})$ with floor, $\mathrm{Sx} / \mathrm{D}=1.0$ mean

\begin{tabular}{|c|c|c|c|c|c|}
\hline \multirow{2}{*}{$\begin{array}{c}\text { Sy/D } \\
(-)\end{array}$} & \multicolumn{5}{|c|}{ Q1/Q2 (Ratio of HRRs) } \\
\cline { 2 - 6 } & 1.0 & 1.5 & 2.0 & 2.5 & 3.0 \\
\hline 0.0 & 37.1 & 42.3 & 48.2 & 52.5 & 58.5 \\
\hline 0.5 & 33.1 & 40.8 & 45.6 & 51.6 & 57.1 \\
\hline 1.0 & 32.9 & 39.8 & 44.5 & 51.9 & 56.9 \\
\hline 1.5 & 32.7 & 40.0 & 44.3 & 51.6 & 57.0 \\
\hline 2.0 & & & & & \\
\hline 3.0 & 32.7 & 39.9 & 44.3 & 51.0 & 56.6 \\
\hline 5.0 & & & & & \\
\hline
\end{tabular}
standard deviation

\begin{tabular}{|c|c|c|c|c|c|}
\hline \multirow{2}{*}{$\begin{array}{c}\text { Sy/D } \\
(-)\end{array}$} & \multicolumn{5}{|c|}{ Q1/Q2 (Ratio of HRRs) } \\
\cline { 2 - 6 } & 1.0 & 1.5 & 2.0 & 2.5 & 3.0 \\
\hline 0.0 & 5.2 & 5.4 & 5.9 & 6.7 & 6.6 \\
\hline 0.5 & 5.1 & 5.5 & 5.1 & 7.2 & 7.6 \\
\hline 1.0 & 5.0 & 6.0 & 5.2 & 6.2 & 7.5 \\
\hline 1.5 & 4.1 & 6.5 & 6.5 & 6.5 & 7.2 \\
\hline 2.0 & & & & & \\
\hline 3.0 & 5.5 & 6.5 & 5.8 & 6.8 & 8.2 \\
\hline 5.0 & & & & & \\
\hline
\end{tabular}

Table 1-4 Mean and Std. of flame height $(\mathrm{cm})$ with floor, $\mathrm{Sx} / \mathrm{D}=1.5$ mean

\begin{tabular}{|c|c|c|c|c|c|}
\hline \multirow{2}{*}{$\begin{array}{c}\text { Sy/D } \\
(-)\end{array}$} & \multicolumn{5}{|c|}{ Q1/Q2 (Ratio of HRRs) } \\
\cline { 2 - 6 } & 1.0 & 1.5 & 2.0 & 2.5 & 3.0 \\
\hline 0.0 & 35.9 & 41.6 & 47.2 & 51.2 & 57.3 \\
\hline 0.5 & 32.9 & 40.9 & 45.9 & 51.4 & 57.1 \\
\hline 1.0 & 32.7 & 39.9 & 44.7 & 51.7 & 56.3 \\
\hline 1.5 & & & & & \\
\hline 2.0 & & & & & \\
\hline 3.0 & 32.7 & 39.8 & 44.7 & 50.9 & 56.4 \\
\hline 5.0 & & & & & \\
\hline
\end{tabular}
standard deviation

\begin{tabular}{|c|c|c|c|c|c|}
\hline \multirow{2}{*}{$\begin{array}{c}\text { Sy/D } \\
(-)\end{array}$} & \multicolumn{5}{|c|}{ Q1/Q2 (Ratio of HRRs) } \\
\cline { 2 - 6 } & 1.0 & 1.5 & 2.0 & 2.5 & 3.0 \\
\hline 0.0 & 4.9 & 5.3 & 5.7 & 5.9 & 6.2 \\
\hline 0.5 & 5.7 & 5.3 & 5.7 & 6.8 & 7.1 \\
\hline 1.0 & 4.6 & 6.0 & 5.2 & 5.8 & 7.3 \\
\hline 1.5 & & & & & \\
\hline 2.0 & & & & & \\
\hline 3.0 & 5.0 & 5.8 & 6.8 & 6.9 & 6.3 \\
\hline 5.0 & & & & & \\
\hline
\end{tabular}

height, $\mathrm{L}_{\mathrm{m}} / \mathrm{L}_{\mathrm{mo}}$, as a function of floor effect in dimensionless elevation of $\mathrm{h} / \mathrm{D}$. Where $\mathrm{L}_{\mathrm{mo}}$ is the merged flame height without separations between the six burners. As the elevation, h, exceed $0.2 \mathrm{~m}$ or lower, $h / D \geq 1$, no obvious difference was found on the merged flame heights so that we adopted this situation as the case of without floor. Table 1-5 to 1-8 are the results of merged flame heights without floor effect as setting the elevation of $h=-0.3 \mathrm{~m}$. We adopted the case of with floor as setting the elevation of $\mathrm{h}=0 \mathrm{~cm}$ and without floor case as setting of $\mathrm{h}=-0.3 \mathrm{~m}$ wa s e mployed, respectively..

\section{(b) Structure of Merged} Flame

Figure 5-1 shows the contour maps of the upward velocities with and without the floor in the Y-Z elevation at the center of longitudinal length of the array of three fire sources. When no separation is given to the system, Figure 5-1 (a), flame and hot current merged just above the floor. As separation are taken at greater distance the merging point (or zone in 3-dimensional space) moved upward along the trajectory and showed greater upward velocity. Every hot currents flew and merged up with each other including entrainment from ambient air and resulted the one merged upward flow showing greater upward velocity than its one in lower part. When no floor effect is given to the system, we also observed the merging of the flow as shown in Figure 5-1(e), however, the merging point (or zone) moves higher than the one with floor.

Figure 5-2 shows the isothermal lines obtained under the same conditions in Figure 5-1. If we adopt the delineation of the excess temperatures of $400 \mathrm{~K}-500 \mathrm{~K}$, the observed flame 
Table 1-5 Mean and Std. of flame height $(\mathrm{cm})$ without floor, $\mathrm{Sx} / \mathrm{D}=0.0$

mean

\begin{tabular}{|c|c|c|c|c|c|}
\hline \multirow{2}{*}{$\begin{array}{c}\text { Sy/D } \\
(-)\end{array}$} & \multicolumn{5}{|c|}{ Q1/Q2 $^{-}$(Ratio of HRRs) } \\
\cline { 2 - 6 } & 1.0 & 1.5 & 2.0 & 2.5 & 3.0 \\
\hline 0.0 & 50.8 & 56.1 & 64.1 & 65.1 & 72.3 \\
\hline 0.5 & 41.8 & 48.5 & 57.6 & 62.2 & 66.6 \\
\hline 1.0 & 40.4 & 45.3 & 54.1 & 60.2 & 65.4 \\
\hline 1.5 & 41.0 & 44.6 & 55.0 & 60.7 & 64.3 \\
\hline 2.0 & 40.5 & 46.3 & 55.6 & 59.7 & 64.4 \\
\hline 3.0 & 41.5 & 46.1 & 55.4 & 59.6 & 64.5 \\
\hline 5.0 & & & & & \\
\hline
\end{tabular}

standard deviation

Table 1-5 Mean and Std. of flame height $(\mathrm{cm})$

without floor, $\mathrm{Sx} / \mathrm{D}=0.5$

mean

\begin{tabular}{|c|c|c|c|c|c|}
\hline \multirow{2}{*}{$\begin{array}{c}\text { Sy/D } \\
(-)\end{array}$} & \multicolumn{5}{|c|}{ Q1/Q2 (Ratio of HRRs) } \\
\hline 0.0 & 47.9 & 1.5 & 2.0 & 2.5 & 3.0 \\
\hline 0.5 & 41.9 & 48.9 & 56.4 & 64.1 & 67.8 \\
\hline 1.0 & 42.0 & 45.8 & 55.3 & 62.6 & 66.7 \\
\hline 1.5 & & & & & \\
\hline 2.0 & 40.8 & 44.1 & 51.6 & 56.4 & 62.9 \\
\hline 3.0 & & & & & \\
\hline 5.0 & & & & & \\
\hline
\end{tabular}

standard deviation

Table 1-5 Mean and Std. of flame height $(\mathrm{cm})$ without floor, $\mathrm{Sx} / \mathrm{D}=1.0$

mean

\begin{tabular}{|c|c|c|c|c|c|}
\hline \multirow{2}{*}{$\begin{array}{c}\text { Sy/D } \\
(-)\end{array}$} & \multicolumn{5}{|c|}{ Q1/Q2 (Ratio of HRRs) } \\
\cline { 2 - 6 } & 1.0 & 1.5 & 2.0 & 2.5 & 3.0 \\
\hline 0.0 & 46.0 & 53.3 & 57.4 & 63.1 & 67.9 \\
\hline 0.5 & 41.7 & 48.4 & 56.7 & 62.4 & 66.7 \\
\hline 1.0 & 41.9 & 46.0 & 54.0 & 60.9 & 64.9 \\
\hline 1.5 & 41.3 & 45.7 & 54.9 & 61.0 & 64.8 \\
\hline 2.0 & & & & & \\
\hline 3.0 & 41.7 & 45.9 & 55.4 & 60.9 & 64.9 \\
\hline 5.0 & & & & & \\
\hline
\end{tabular}

standard deviation

Table 1-5 Mean and Std. of flame height $(\mathrm{cm})$

without floor, $\mathrm{Sx} / \mathrm{D}=1.0$

mean

\begin{tabular}{|c|c|c|c|c|c|}
\hline \multirow{2}{*}{$\begin{array}{c}\text { Sy/D } \\
(-)\end{array}$} & \multicolumn{5}{|c|}{ Q1/Q2 (Ratio of HRRs) } \\
\hline 0.0 & 42.7 & 48.4 & 56.6 & 62.5 & $\mathbf{6 6 . 0}$ \\
\hline 0.5 & 41.8 & 48.5 & 56.6 & 62.1 & 66.7 \\
\hline 1.0 & 41.7 & 45.8 & 55.0 & 60.2 & 64.7 \\
\hline 1.5 & & & & & \\
\hline 2.0 & & & & & \\
\hline 3.0 & 41.9 & 45.7 & 55.4 & 59.9 & 64.9 \\
\hline 5.0 & & & & & \\
\hline
\end{tabular}

standard deviation

\begin{tabular}{|c|c|c|c|c|c|}
\hline \multirow{2}{*}{$\begin{array}{c}\text { Sy/D } \\
(-)\end{array}$} & \multicolumn{5}{|c|}{ Q1/Q2 (Ratio of HRRs) } \\
\hline 0.0 & 5.3 & 1.5 & 2.0 & 2.5 & 3.0 \\
\hline 0.5 & 6.4 & 6.9 & 7.2 & 6.7 & 9.1 \\
\hline 1.0 & 8.0 & 8.2 & 8.0 & 7.7 & 9.2 \\
\hline 1.5 & & & & & \\
\hline 2.0 & & & & & \\
\hline 3.0 & 4.6 & 6.6 & 6.2 & 6.5 & 6.8 \\
\hline 5.0 & & & & & \\
\hline
\end{tabular}

height, continuous flame height, agreed almost with the regions of these excess temperatures. And it is clearly shown how the flame merge together on the center part of the trajectory and how the merged flame height depends on the space not only between two arrays of fire sources but also inner space within each array.

It is necessary to investigate the merging behavior and structure of the merged flame(s) and hot current for the purpose of quantitative understanding and establish the modeling on the correction factor which evaluates the height of merged flame(s). Based on the data of excess temperature and upward velocity which were measured in 3 dimensional space and time-averaged ones, the 3D-structure of excess temperature and upward velocity are visualized as shown in Figure 7. The elevation, $\mathrm{h}$, between the burner surface to the floor were changed in the range of $\mathrm{h}=0 \mathrm{~m}$ to $\mathrm{h}=-0.3 \mathrm{~m}$ and also the space between two arrays was changed. These figures were constructed using the time-space averaged values, $(3 \mathrm{~min}$ and $5 \times 5 \times 5 \mathrm{~cm}^{3}$ volumetric averaging method was carried out), so that the representative structure includes some obscurity and which might reflect in visualization. The same method of time-space averaging used for the excess temperature was employed for the evaluation of upward velocity structure visualization, so that it is very hard to investigate the fine structure comes from fluctuation or eddy in the transition and merging region where the multi continuous flames merge together showing the transition from flame to intermittent flame. For those reason, our interest was concentrated on the continuous flame height to evaluate 


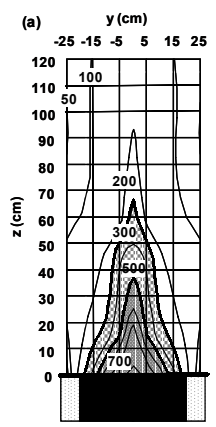

(b)
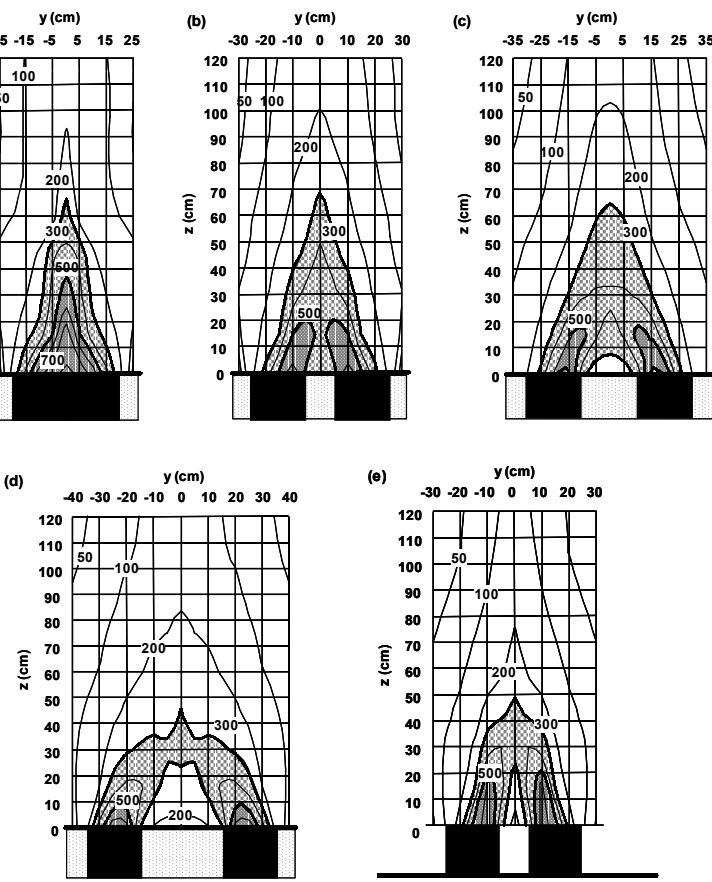

Isother $m$ curves under the various experimental condition.

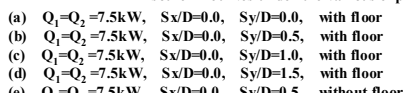

(c) $\mathrm{Q}_{1}=\mathrm{Q}_{2}=7.5 \mathrm{~kW}, \quad \mathrm{~S} / \mathrm{D}=0.0, \quad \mathrm{~S} / \mathrm{D}=1.0$

$\begin{array}{lll}\text { (d) } \mathrm{Q}_{1}=\mathrm{Q}_{2}=7.5 \mathrm{~kW}, & \mathrm{Sx} / \mathrm{D}=0.0, & \mathrm{Sy} / \mathrm{D}=1.5, \text { with floor } \\ \text { (e) } \mathrm{Q}_{1}=\mathrm{Q}_{2}=7.5 \mathrm{~kW}, & \mathrm{Sx} / \mathrm{D}=0.0, & \mathrm{Sy} / \mathrm{D}=0.5, \text { without floo }\end{array}$

Figure 5-2 Contour maps of the excess temperature, with and without floor. the flame merging instead of flame tip height which is usually employed to evaluate the flame height.

\section{(c) Modeling}

In order to investigate how the value of power to the correction factor, r.h.s. of equation (3) through to equation (6), changes with the increase in the space between two arrays, Sy, and 2 inner separation of $\mathrm{Sx}$, in each fire sources array, the ratio of $\mathrm{Sb} / \mathrm{Sm}$, that is the ratio between the apparent fire zone area and the real heat releasing area like burning houses, is plotted against the inverse value of the power based on the experiments, where Sm is the total area of fire sources included in the system and becomes $n \bullet \pi(D / 2)^{2}$ in the case of $n$-pieces of fire sources. The apparent burning zone area, $\mathrm{Sb}$, is also defined as $\mathrm{Sb}=6 \pi(\mathrm{D} / 2)^{2}+\mathrm{S}_{\mathrm{y}}\left(3 \mathrm{D}+2 \mathrm{~S}_{\mathrm{x}}\right)+$ $4 \mathrm{D} \bullet \mathrm{S}_{\mathrm{x}}$. The ratio of $\mathrm{Sb} / \mathrm{Sm}$ is considered to be the characteristic di-

mensionless fire intensity depends on fire zone, and which correlates to the value of power to the correction factor on the merged flame height. Figure 6 shows the correlation between the dimensionless fire zone, $\mathrm{Sb} / \mathrm{Sm}$, and the inverse value of power to the correction factor. Where the inverse value is temporally adopted to show clear correlation between $\mathrm{Sb} / \mathrm{Sm}$ vs value of power to the r.h.s. of the model equations. Therefore, we could clearly understand that the value of the power reflects the decreasing mode of the $\mathrm{L} / \mathrm{L}_{\mathrm{m}}$ as a function of the separation of $\mathrm{S}_{\mathrm{y}}$ and which is the governing factor for 2 arrays of the fire sources although the each array includes multi spaces and fire sources. Figure 6 indicates that the value of power to the correction factor starts at $2 / 3$ power and/or $2 / 5$ power as for two line fire sources in parallel configuration and for square fire sources in symmetri-

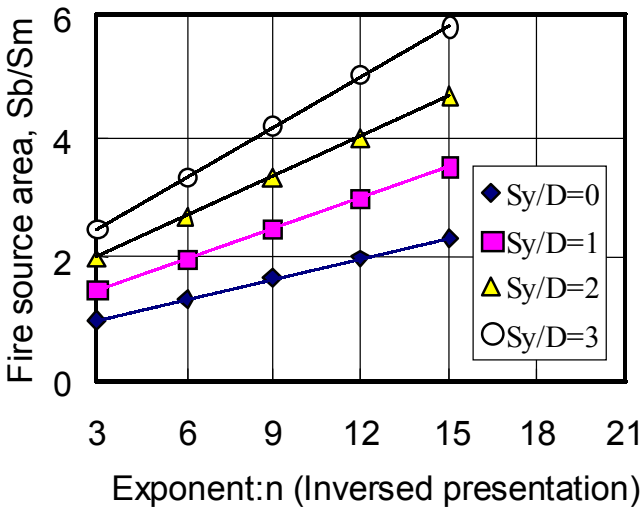

Figure 6 Dimensionless fire zone as the inverse value of power to the correction factor of flame height as it merged with nearby flames. 


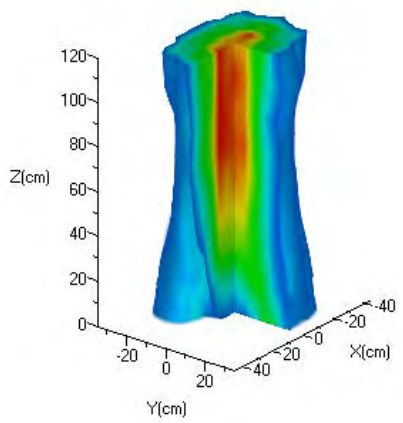

Figure 7-(a) Volume of upward velocity $(\mathrm{m} / \mathrm{s})$.

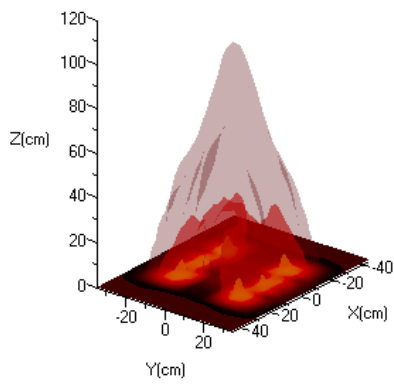

Figure 7-(b) Isosurface of excess temperature (K).

$\mathrm{Q}_{1}=7.5 \mathrm{~kW}, \mathrm{Q}_{2}=7.5 \mathrm{~kW}, \mathrm{SxD}=1.0, \mathrm{Sy} \mathrm{D}=0.0$, Floor level $=0.0(\mathrm{~m})$

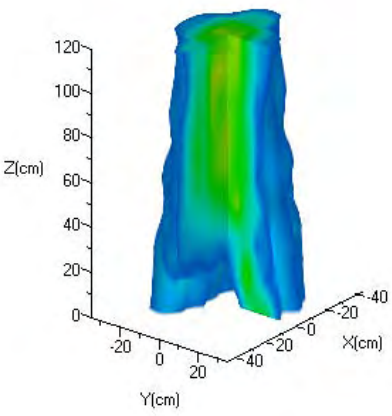

Figure 7-(c) Volume of upward velocity $(\mathrm{m} / \mathrm{s})$.

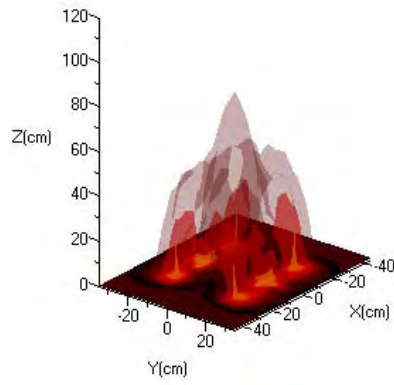

Figure 7-(d) Isosrface of excess temperature $(\mathrm{K})$.

$\mathrm{Q}_{1}=7.5 \mathrm{~kW}, \mathrm{Q}_{2}=7.5 \mathrm{~kW}, \mathrm{SxD}=1.0, \mathrm{Sy} \mathrm{D}=0.0$, Floor level $=-0.3(\mathrm{~m})$
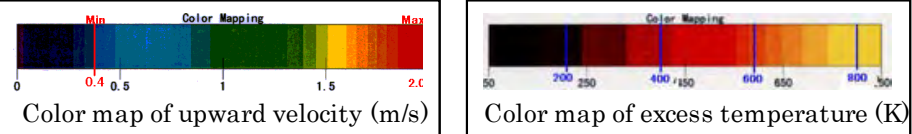

cal configuration, respectively. This indication shows strong supports for the modification which must be installed to the term of power with dimensionless inner separation, $\mathrm{Sx} / \mathrm{D}$, as secondary effect. Then, we employed the power term of $2 /[3(1+2 \cdot S x / D)]$ for equation (3) and $2 /[5(1+2 \cdot S x / D)]$ for equation (4). For the case of flame merging without floor effect, we could expect that the ambient air could be entrained from both sides to the flames which come from each array of the fire sources. Therefore, we assumed the half of the decreasing rate of $1 /[3(1+2 \cdot S x / D)]$ to the power term of equation $(5)$ and $1 /[5(1+2 \cdot S x / D)]$ for equation $(6)$ with counting double area of $2 \mathrm{~S}_{\mathrm{y}}$ instead of $\mathrm{S}_{\mathrm{y}}$ in the correction factor for both equations of (5) and (6).

Based on the consideration and discussion above, it is possible to evaluate the validity of the simple model on the merged flame height as the combined function of $\mathrm{S}_{\mathrm{y}} / \mathrm{D}, \mathrm{S}_{\mathrm{x}} / \mathrm{D}$, ratio of $\mathrm{Q}_{1}$ and $\mathrm{Q}_{2}$, and effect of floor. The merged flame heights were estimated using the equations (3) to (6) for the cases of those with and without floor effect, as are shown in 


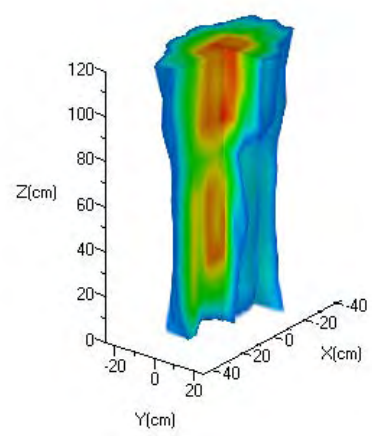

Figure7(e) Volume of upward velocity $(\mathrm{m} / \mathrm{s})$.

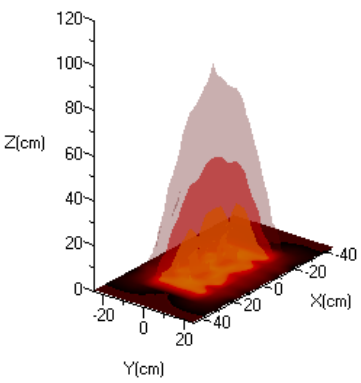

Figure 7-(f) Isosurface of excess temperature $(\mathrm{K})$.

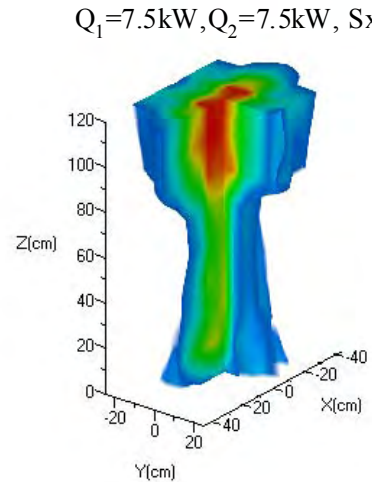

Figure 7-(g) Volume of upward velocity $(\mathrm{m} / \mathrm{s})$.

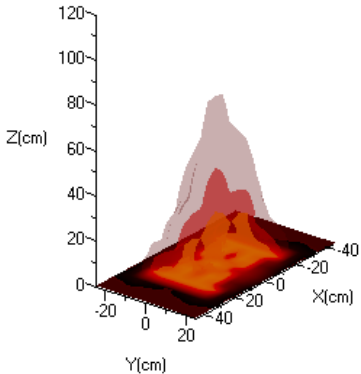

Figure 7-(h) Isosurface of excess temperature $(\mathrm{K})$.

$\mathrm{Q}_{1}=7.5 \mathrm{~kW}, \mathrm{Q}_{2}=7.5 \mathrm{~kW}, \mathrm{SxD}=0.0, \mathrm{Sy}=0.0$, Floor leve $=-0.3(\mathrm{~m})$
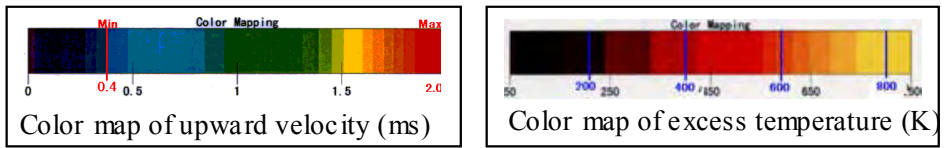

Figure 8. Those estimated flame heights of merged or affected each other by nearby flames are plotted and compared with the mean value of merged flame height in Table 1-1 to 1-8. The height of the merged flame which was formed by ones from six fire sources without separation is defined as the reference length, $\mathrm{L}_{\mathrm{m}}$, and the flame height with arbitrary separation distances of $\mathrm{S}_{\mathrm{x}}$ and $\mathrm{S}_{\mathrm{y}}$ is also defined as $\mathrm{L}$. The dimensionless merged flame height, $\mathrm{L} / \mathrm{L}_{\mathrm{m}}$, is plotted as a function of dimensionless separation distance between arrays, Sy/D. Comparison of calculated and measured merged flame height gave excellent agreement as the changes of the inner spacing are given to the system with and without the presence of the floor effect.

As the ratio of $\mathrm{Q}_{1} / \mathrm{Q}_{2}$ were changed in the range of $\mathrm{Q}_{1} / \mathrm{Q}_{2}=1$ to $\mathrm{Q}_{1} / \mathrm{Q}_{2}=3$, excellent agreement was also given between the calculated merged flame heights and measured ones. The models which consider the effects of the burning area and spaces between separated fire 

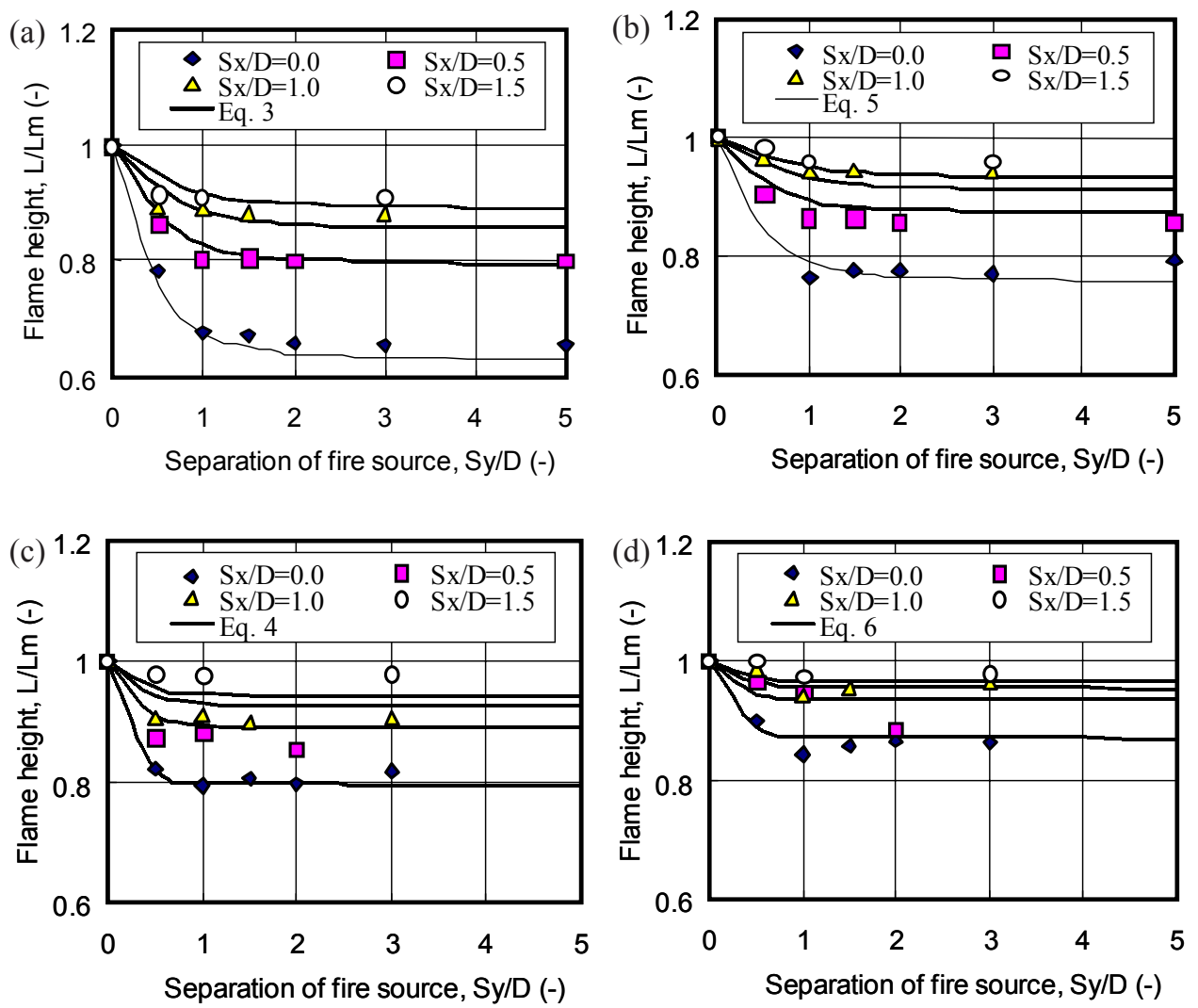

Figure 8 Dimensionless flame height merged or affected with nearby flames as a function of dimesnionless separation, Sy/D changing the inner separation, $\mathrm{Sx} / \mathrm{D}$ in array of fire sources. (a) Q1=Q2 with floor, (b) Q1=Q2 withot floor, (c) Q1 $>$ Q2 with floor, and (d) Q1>Q2 without floor.

sources, like path or alley around the burning houses, are therefore useful for the estimation on the merged flame height from multi fire sources when these some burning houses are coupled into an unit of 2 by 3 configuration in real city fire.

\section{SUMMARY}

An empirical model [12] for flame height estimation from two lines fire sources was modified for the two arrays of fire sources including three separate fire sources with two inner separations with and without floor effect. The dependence of the merged flame height against the function of main separation of fire source arrays and inner separation within the array is different according to the floor effect and also to the ratio of HRR for fire sources array. The model presented here gives the quantitative estimation on merged flame height received the effect of nearby flames. This basic flame behavior is applicable to estimate the flame height in fire front zone of the city fire where a burning house with two other nearby burning houses in both side having the paths and arrays. The presented models on merged flame height will help the understanding of flame behavior with effects of nearby 
flames and give the quantitative estimation.

\section{ACKNOWLEDGMENT}

Authors would like to note our sincere thank to Mr. Koji Hara undergraduate students of Tokyo University of Science, for his eager help in carrying out of this experimental study.

\section{NOMENCLATURES}

D: representative fire size $[\mathrm{m}]$

Do: reference fire size taking a unit length [m]

L: height or length of merged flame [m]

$\mathrm{Lm}$ : flame height or length as no separation given to the multi fire sources [m]

Lmo: flame height or length as no elevation given to the multi fire sources from floor [m]

$\mathrm{Sx}$ : inner space between fire sources which compose a array fire source $[\mathrm{m}]$

Sy: space between array fire sources [m]

$\mathrm{Sb}$ : burning area of multi fire sources in the fire zone $\left[\mathrm{m}^{2}\right]$

$\mathrm{Sm}$ : apparent fire zone including $\mathrm{Sb}$ and space area between fire sources $\left[\mathrm{m}^{2}\right]$

\section{REFERENCES}

1) Yokoi, S., BRI Report 34, Japanese Ministry of Construction, (1960)

2) Morton, B. R., G. Taylor and Turner, Proc. of the Royal Society (London), A234, 123

3) Thomas, P. H., Ninth Symposium (International) on Combustion, 84, 4-859, (1963)

4) McCaffrey, B. J., "Purely buoyant diffusion flames: Some Experimental Results", NBS Report, No NBSIR79-1910 (1979)

5) Cox, G. and Chitty, R., Combustion and Flame 39:191-201 (1980)

6) Zukoski, E. E., 1st Symposium (International) on Fire Safety Science, 1-11, (1985)

7) Steward, F. R., Combustion and Flame 8:171-178, (1964) and Combustion Science and Technology, 2:203-212 (1970)

8) Quintier, J G., and Grove, B “Correlations for Fire Plumes", NIST-GCR-98-744

9) Sugawa, O., Sato, H., and Oka, Y., 3rd Symposium (International) on Fire Safety Science, 435-445, (1991)

10) Putnam A. A., and Speich, C. F., 9th Symposium (International) on Combustion, 867877, (1963)

11) Thomas, P. H., 10th Symposium (International) on Combustion, 983-986, (1965)

12) Sugawa, O., and Takahashi, W., Fire and Materials, vol.17, 111-117, (1993) 